\title{
The Effect of Proactive Personality on Individual Improvisation: The Moderating Role of Job Autonomy
}

\author{
Xuehui Wu, Yinqiu Ma* \\ Business School, Nanjing Normal University, Nanjing, China \\ Email: 18903781913@163.com
}

How to cite this paper: $\mathrm{Wu}, \mathrm{X} . \mathrm{H}$. and $\mathrm{Ma}$, Y.Q. (2019) The Effect of Proactive Personality on Individual Improvisation: The Moderating Role of Job Autonomy. Open Journal of Social Sciences, 7, 178-190. https://doi.org/10.4236/jss.2019.74015

Received: March 22, 2019

Accepted: April 13, 2019

Published: April 16, 2019

Copyright $\odot 2019$ by author(s) and Scientific Research Publishing Inc. This work is licensed under the Creative Commons Attribution International License (CC BY 4.0).

http://creativecommons.org/licenses/by/4.0/

\section{(c) (i) Open Access}

\begin{abstract}
The trigger mechanism of individual improvisation needs further research. Based on social cognitive theory and job characteristics model theory, this paper establishes the relationship model between proactive personality and individual improvisation, regarding self-efficacy as a mediator and job autonomy as a moderator. Through regression analysis of 298 samples, the results show that proactive personality is positively related to individual improvisation, and self-efficacy plays a role of intermediary mechanism in this relationship. Besides, we also find out that job autonomy has a regulatory effect on the relationship between self-efficacy and individual improvisation. This research provides a reference for arousing and managing individual improvisation.
\end{abstract}

\section{Keywords}

Proactive Personality, Individual Improvisation, Self-Efficacy, Job Autonomy

\section{Introduction}

Faced with the uncertainty, variability and ambiguity of the economic environment, organizations will face multiple development obstacles in accordance with fully formal plans and scheduled arrangements. Therefore, organizations need to adopt flexible, improvisational and fast actions to respond to various exceptions or grasp instantaneous opportunities [1]. As a spontaneous and creative behavior [2], improvisation can help organizations respond quickly to changes in market environment and customer demand, which can enhance organizational effectiveness [2]. Therefore, improvisation has been valued by many scholars.

As the foundation of organizational improvisation, individual improvisation 
can drive organization to change through employee practice [3]. Numerous studies have explored the influencing factors of improvisation including organizational factors [4], team factors [5] and personal factors [6]. The personal characteristics factors mainly focus on the individual's ability and psychological aspects, while few studies examine the influence of individual's personality characteristics on individual's improvisational behavior. The employees with highly proactive personality are not bound by the external environment and would adopt positive actions to solve organizational trouble [7]. Because of possessing strong intrinsic behavioral motivation [8] and ability self-confidence [9], they can emerge improvisation when facing unexpected condition. In addition, the occurrence of individual improvisation is not only influenced by the individual's psychology but also by the external organization environment. Job autonomy, an important environmental factor, may generate a significant impact on employee motivation and behavior [10].

In view of this, this paper intends to investigate the effect of proactive personality on individual improvisation and the role mechanism of self-efficacy and job autonomy. Specifically, the theoretical contributions of this paper are as follows: Firstly, this study supplements previous research and explores the most fundamental influencing factor of improvisation from the personality trait perspective. Secondly, according to the social cognitive theory and job characteristics model theory, we research the intrinsic black box and boundary condition of the influence of proactive personality on employee improvisational behavior. This paper systematically analyzes the influence of personality trait on individual improvisation in order to provide useful guidance for enterprises to better manage and utilize employee improvisation.

\section{Literature Review}

\subsection{Proactive Personality and Individual Improvisation}

Improvisation first appeared in jazz and theater performance, then Weick (1998) [11] firstly introduced the concept of improvisation to the field of business management as a metaphor. Vera and Crossan [2] argued that improvisational behavior is a role-out-behavior in which employee used his spontaneity and creativity to find new method in order to solving unexpected real problem. The essence is that employees simultaneously plan and act for the purpose of handling urgent accident, thus organization can get rid of the crisis and improve performance. However, employees are not standardized products, different individuals have different cognitive and behavioral responses. Specifically, proactive personality trait represents a specific and stable response tendency of individual to environmental changes. Through meta-analysis, Fuller and Marler (2009) [12] found that employees with proactive personality traits were more enterprising and responsible for constructive change, in addition, they were good at finding problems, capturing opportunities, and proactively demonstrating Out-of-role behaviors. In an emergency, individuals with proactive personality can get rid of 
environmental constraints, find out opportunities, and respond creatively. Furthermore, Thompson (2005) [13] based on the social capital theory and pointed out that individuals with high-proactive personality would take the initiative to assume the responsibility, and then improving work performance. Therefore, when encountering emergency, employees with high-proactive personality have stronger responsible sense, stimulate internal motivation, be good at discovering the nature of the problem, and then performing improvisation spontaneously and creatively. On the basis of these considerations, we hypothesize that:

Hypothesis 1: Proactive personality will be positively related to individual improvisation.

\subsection{Proactive Personality and Self-Efficacy}

As an important part of social cognitive theory [14], self-efficacy is a confident belief in self-ability when engaging in specific work. This belief affects an individual's attitude towards difficulty, the level of individual effort, and the persistence of overcoming challenges. As a subjective cognition, self-efficacy perceives the influence of individual personality traits. Bindl \& Parker (2011) [15] found that individuals with high-proactive personality tend to gain more sense of job control, thereby enhancing their responsibility and self-efficacy. Individuals with strong proactive personality tend to actively change the working environment rather than being restricted, they have the confidence to solve the difficulties encountered so that taking action and persevering. Therefore, individuals with high proactive personality have a firm belief in success, actively create an environment, and enhance the sense of work control. When he successfully changes the environment, his self-confidence can be enhanced and self-efficacy will be also significantly improved. Brown (2006) [16] also confirmed that high-proactive individuals have higher self-efficacy, they are convinced that they can complete an activity or task, and persist in a field for a longer period of time, thus showing better Job search results. Collectively, we hypothesize that:

Hypothesis 2: Proactive personality will be positively related to self-efficacy.

\subsection{Self-Efficacy and Individual Improvisation}

According to social cognitive theory, individuals with high self-efficacy have strong self-confidence and motivation for their choices, and stimulate individual to produce target behavior through internal self-motivation [17]. improvisational behavior is a stressful behavior of employees in emergencies, which is challenging and requires strong self-confidence and good self-perception. Employees with high self-efficacy believe that they can overcome the challenges in the environment. With the confidence in their coping ability, they have more positive comments on improvisation and expect that their improvisational behavior can produce good results, Meanwhile, high self-efficacy Individuals believe that they have the ability to deal with the external influences of improvisation. On the contrary, employees with low self-efficacy show less improvisation due to their 
lack of self-confidence, and adopt more disciplined methods to deal with unexpected problems. Ding and Chen (2017) [6] found that individuals with high self-efficacy are more positive about the expectations of individual outcome, thus they are more inclined to take improvisation. Therefore, we hypothesize that:

Hypothesis 3: Self-efficacy will be positively related to individual improvisation. Consistent with theories of personal control, more proactive individuals should have a greater sense of self-determination and self-efficacy in their work lives [18]. Confidence in ability will prompt individual to take improvisational behavior. On the contrary, employees with lower proactive personality are more likely to be shaped by the environment when they encounter unexpected problems [7]. For lacking a sense of control over the environment, individual get a lower sense of self-efficacy that would hinder their improvisation. Studies have shown that self-efficacy plays a mediating role in the proactive personality mechanism. Based on the cognitive-motivational theory, Parker (2006) [19] proposed an antecedent variable model of proactive behavior in which proactive personality influences initiative behavior through intermediary motivation mechanisms such as role breadth self-efficacy. Individuals with high proactive personality have stronger sense of control and self-efficacy, so they can show stronger problem-solving ability and creativity in the face of difficulties in work, and adopt improvisation for Improving organizational effectiveness. Therefore, we hypothesis that:

Hypothesis 4: Self-efficacy will mediate the relationship of proactive personality and individual improvisation.

\subsection{Moderating Role of Job Autonomy}

Job autonomy refers to the degree to which the job provides substantial freedom, independence, and discretion to the individual in scheduling the work and in determining the procedures to be used in carrying it out [20]. The job characteristics model indicates that job autonomy has an important impact on employee motivation and behavior [21]. When work autonomy is high, employees will feel the responsibility of their work and focus more on achieving their work goals. In addition, a high degree of work autonomy allows employees to think more freely and act proactively to respond to threats or challenging work tasks. The study found that individual improvisation is influenced by the interaction between the work environment and the employee's mental state [22]. A high level of job autonomy enables employees to have the opportunity to creatively integrate existing resources in the event of an emergency [23], even for employees with low self-efficacy can response creatively and act initiative in a self-determining environment. When job autonomy is low, it means that employees must strictly follow the prescribed procedures. Even if they have a high sense of self-efficacy, they lack the motivation to act creatively, and thus exhibit less improvisation. Therefore, we argue that: 
Hypothesis 5: Job Autonomy and Self-efficacy have interaction effect on Individual Improvisation.

Therefore, employees with high proactive personality have a stronger environmental control perception which resulting in a higher self-efficacy. In the case of higher job autonomy, self-efficacy can promote employee improvisation. The theoretical model of this study is shown in Figure 1, we study the relationship between proactive personality and employee improvisation relationship from the perspective of psychological resources, regarding self-efficacy as a mediator and job autonomy as a moderator.

\section{Research Methods}

\subsection{Research Design}

Participants were organization employees from a high-tech industrial zone in Henan Province. The data was collected by questionnaires. In order to ensure the authenticity of the information, we made a commitment that the data is only used for academic research and personal privacy will not be revealed, all respondents volunteered to participate in the survey. We distributed 340 questionnaires, after eliminating invalid and incomplete data, 298 valid questionnaires were returned, and recovery rate was $87.64 \%$. Table 1 reflects the demographic characteristics of the data which we used in this paper.

\subsection{Measurement}

The selection of the measurement indicators influences the reliability and validity of the final survey data. Therefore, we drew on the maturity scales of relevant variables abroad and made necessary revisions. As a result, these items were designed in the form of 7-point Likert scales, and respondents are required to rate the Chinese items, rating from $1=$ strongly disagree to $7=$ strongly agree.

Proactive personality. We adapted Parker's (1998) [24] Simplified Scale to measure employee proactive personality. The scale contains six items, for example "If I see something I don't like, I fix it." The Cronbach's alpha coefficient of the scale was 0.909 .

Self-efficacy. We used the general self-efficacy scale, which offered by Schwarzer's (1997) [25], to assess employee self-efficacy. There are ten items in the scale, one sample item was "I am confident that I could deal efficiently with unexpected events." The Cronbach's alpha coefficient of the scale was 0.931 .

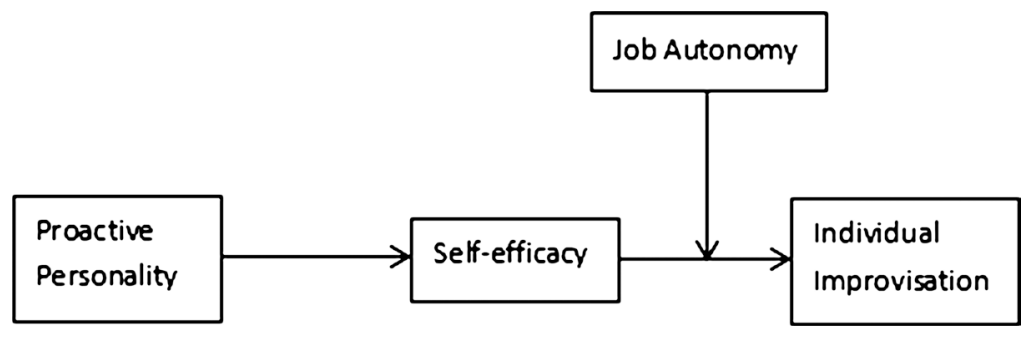

Figure 1. Theoretical model. 
Table 1. Demographic characteristics of the analytic sample.

\begin{tabular}{clcc}
\hline \multirow{2}{*}{ Demographic characteristics } & Unweighted n's & Weighted Percentages \\
\hline \multirow{2}{*}{ Gender } & Male & 126 & $42.3 \%$ \\
& Female & 172 & $57.7 \%$ \\
\hline \multirow{2}{*}{ Age } & $<25$ & 52 & $17.5 \%$ \\
& $25-35$ & 188 & $63.1 \%$ \\
& $>35$ & 58 & $19.4 \%$ \\
\hline \multirow{3}{*}{ Education } & associate degree or below & 54 & $18.1 \%$ \\
& Bachelor's degree & 152 & $51.1 \%$ \\
& Master's degree or above & 92 & $30.8 \%$ \\
\hline \multirow{3}{*}{ Staff Type } & technology & 132 & $44.3 \%$ \\
& sales & 57 & $19.2 \%$ \\
& management & 38 & $12.6 \%$ \\
& others & 71 & $23.9 \%$ \\
\hline & $\leq 1$ & 75 & $25.2 \%$ \\
& $2-3$ & 80 & $26.8 \%$ \\
& $4-5$ & 48 & $16.1 \%$ \\
& $6-9$ & 53 & $17.8 \%$ \\
& $\geq 10$ & & $14.1 \%$ \\
\hline
\end{tabular}

Notes: $\mathrm{N}=298$.

Individual Improvisation. We employed Vera \& Crossan (2005) [2] scale to measure the creativity and spontaneity of participants. The scale includes seven items, for example: "I can deal with unanticipated events on the spot." The Cronbach's alpha coefficient of the scale was 0.949 .

Job autonomy. We applied Spreitzer's (1995) [26] work autonomy scale to measure employee autonomy. The scale contains 3 items, for example: "I have Significant autonomy in determining how I do my job.” The Cronbach's alpha coefficient of the scale was 0.879 .

Control variables. In the present study, we developed three control variables in order to minimize the interference of exogenous variables, including participants' age, education, and service years.

\subsection{Analysis Method}

Using SPSS 22.0 and AMOS 23.0 data analysis software to analyze the data of the study. First, we verified the reliability and validity of the scale by confirmatory factor analysis. Secondly, we employed descriptive statistical analysis and hierarchical analysis method to prove the main effect and the mediation effect, then using the boot-strapping method to further test the mediating effect of self-efficacy. Finally, we test the regulatory effect of job autonomy using hierarchical regression analysis method, and drawn the interactive effect figure. 


\section{Results}

\subsection{Factor Analysis}

In order to measure the reliability and validity of latent variable scales, we performed factor analysis on the data. The results of the KMO values of four latent variables (proactive personality, self-efficacy, individual improvisation, job autonomy) were $0.909,0.933,0.917$, and 0.753 , which indicated that scales were suitable for factor analysis. Cronbach's alpha, as the reliability coefficient, are greater than 0.8 , which represented that the questionnaire has favorable reliability. The factor loading were all above 0.6 , which means well structural validity. Using Amos 23.0 software to develop confirmatory factor analysis on sample data. From the results in Table 2, the model fitting indexes of the questionnaires used in the study were good $\left(\chi^{2} / \mathrm{df}=2.978, \mathrm{RMSEA}=0.082, \mathrm{IFI}=0.913, \mathrm{CFI}=\right.$ 0.913 , TLI $=0.903)$, indicating that each questionnaire has good discriminant validity.

\subsection{Descriptive Statistics}

Table 3 reports the mean, standard deviation, and correlation coefficients of the variables. There was no abnormality in the mean and standard deviation. The results showed that proactive personality was positively correlated with employee Improvisation $(r=0.753, p<0.001)$, hypothesis 1 was validated; proactive personality

Table 2. Confirmatory factor analysis.

\begin{tabular}{ccccccc}
\hline Model & Factor & $\chi^{2} / \mathrm{df}$ & RMSEA & IFI & CFI & TLI \\
\hline Four-factor model & PP, SE, JA, II & 2.978 & 0.082 & 0.913 & 0.913 & 0.903 \\
Three-factor model & PP, SE + JA, II & 3.340 & 0.102 & 0.832 & 0.850 & 0.826 \\
Two-factor model & PP + SE + JA, II & 3.870 & 0.113 & 0.753 & 0.723 & 0.630 \\
Single factor model & PP + SE + JA + II & 4.235 & 0.137 & 0.712 & 0.712 & 0.605 \\
\hline
\end{tabular}

Notes: PP = Proactive Personality, SE = Self-efficacy, JA = Job Autonomy, II = Individual Improvisation.

Table 3. Mean, standard deviations, and correlations among study variables.

\begin{tabular}{lccccccc}
\hline & 1 & 2 & 3 & 4 & 5 & 6 & 7 \\
\hline 1. Age & 1.000 & & & & & & \\
2. Education & 0.061 & 1.000 & & & & & \\
3. Service Years & $0.654^{* *}$ & $0.300^{* * *}$ & 1.000 & & & & \\
4. Proactive Personality & 0.108 & $-0.123^{*}$ & 0.057 & 1.000 & & & \\
5. Self-efficacy & 0.088 & -0.080 & 0.025 & $0.549^{* * *}$ & 1.000 & & \\
6. Job Autonomy & 0.058 & -0.088 & -0.048 & $0.681^{* * *}$ & $0.638^{* * *}$ & 1.000 & \\
7. Improvisation & 0.132 & $-0.117^{*}$ & 0.075 & $0.753^{* * *}$ & $0.617^{* * *}$ & $0.632^{* * *}$ & 1.000 \\
\multicolumn{1}{c}{ Mean } & 1.340 & 2.150 & 1.690 & 5.175 & 4.764 & 5.015 & 5.077 \\
\multicolumn{1}{c}{$\mathrm{SD}$} & 0.768 & 0.728 & 0.729 & 1.024 & 1.162 & 1.309 & 1.042 \\
\hline
\end{tabular}

Notes: Notes: $\mathrm{N}=298,{ }^{* * *} \mathrm{P}<0.001 ;{ }^{* *} \mathrm{P}<0.01 ;{ }^{*} \mathrm{P}<0.05$. 
and employee self-efficacy also had a significantly positive correlation $(\mathrm{r}=0.549$, $\mathrm{p}<0.001$ ), supporting hypothesis 2 ; self-efficacy can positively influence employee Improvisation $(\mathrm{r}=0.617, \mathrm{p}<0.001)$, and hypothesis 3 was proved. Job autonomy was also positively correlated with employee Improvisation $(r=0.632$, $\mathrm{p}<0.001$ ), it provided a basis for further regulation effect analysis.

\subsection{Mediating Effect}

To further test and verify the intermediary role of self-efficacy, we applied the boot-strapping approach to examine its significance again. Results (see Table 4) showed that in $95 \%$ confidence intervals, the coefficient between proactive personality and individual improvisation was significant $(\beta=0.59, \mathrm{p}<0.001)$. Similarly, we also calculated the coefficients between both proactive personality and self-efficacy $(\beta=0.39, \mathrm{p}<0.001)$ and self-efficacy and individual improvisation $(\beta=0.39, \mathrm{p}<0.001)$, they were all significant. Therefore, Hypotheses 1,2 and 3 were verified. Naturally, Hypothesis 4 was supported. Namely, self-efficacy mediates the relationship between proactive personality and individual improvisation. Considering that the coefficient between proactive personality and individual improvisation was significant $(\beta=0.59, \mathrm{p}<0.001)$. Therefore, self-efficacy will partially mediate the effect of proactive personality on individual improvisation.

As a result, Figure 2 shows the theoretical model of present study and the various coefficient between three variables.

\subsection{Regulatory Effect}

The regulatory effect of job autonomy is shown in Table 5. From Model 2 and

Table 4. Parameter estimates of the mediation model and $95 \%$ confidence intervals.

\begin{tabular}{ccc}
\hline & estimates effect & $95 \%$ CI \\
\hline Direct effects & & \\
Proactive Personality $\rightarrow$ Individual Improvisation & $0,59^{\star * *}$ & {$[0.257,0.544]$} \\
Proactive Personality $\rightarrow$ Self-efficacy & $0.39^{\star * *}$ & {$[0.323,0.516]$} \\
Self-efficacy $\rightarrow$ Individual Improvisation & $0.39^{\star * *}$ & {$[0.271,0.464]$} \\
Indirect effects & & \\
Proactive Personality $\rightarrow$ Self-efficacy $\rightarrow$ Individual Improvisation & $0.15^{\star *}$ & {$[0.108,0.253]$} \\
\hline
\end{tabular}

Notes: $\mathrm{N}=298,{ }^{* *} \mathrm{P}<0.001 ;{ }^{* *} \mathrm{P}<0.01 ;{ }^{*} \mathrm{P}<0.05$

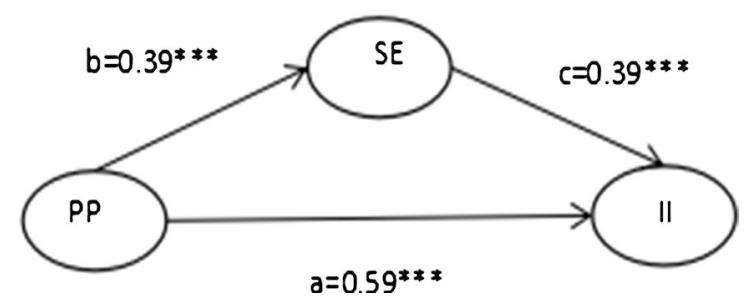

Notes: $\mathrm{N}=298,{ }^{\star * *} \mathrm{P}<0.001 ;{ }^{\star *} \mathrm{P}<0.01 ;{ }^{\star} \mathrm{P}<0.05$.

Figure 2. Standardized path coefficients. 
Model 3, it can be seen that the coefficient of interaction between self-efficacy and job autonomy is significant $(\beta=0.064, \mathrm{p}<0.05)$, so Hypothesis 5 is verified. This study draws the relationship between self-efficacy and employee improvisation under different job autonomy levels in Figure 3. The results of Figure 3 show that the stronger the work autonomy, the effect of self-efficacy on employee improvisation is stronger. With high job autonomy, employees can think more freely and act proactively to respond to threats. even though the employees with low self-efficacy can response creatively and act initiative in a self-determining environment.

\section{Discussion}

The improvisation of employees is extremely important in the field of organizational

Table 5. The interaction analysis of self-efficacy and job autonomy on individual improvisation.

\begin{tabular}{cccc}
\hline Dependent variable & \multicolumn{3}{c}{ Individual Improvisation } \\
\hline Model & Model 1 & Model 2 & Model 3 \\
\hline Age & 0.027 & 0.065 & 0.061 \\
Education & 0.016 & 0.054 & 0.042 \\
Service Years & 0.165 & 0.061 & 0.054 \\
Self-efficacy & & $0.471^{* * *}$ & $0.461^{* * *}$ \\
Job Autonomy & & $0.321^{* * *}$ & $0.353^{* * *}$ \\
Self-efficacy $\times$ Job Autonomy & & & $0.064^{*}$ \\
$\mathrm{R}^{2}$ & 0.019 & 0.485 & 0.492 \\
$\Delta \mathrm{R}^{2}$ & & 0.466 & 0.007 \\
$\mathrm{~F}$ & 1.870 & $55.069^{* * *}$ & $47.054^{* * *}$ \\
$\Delta \mathrm{F}$ & & $45.740^{* * *}$ & $4.077^{\star}$ \\
\hline
\end{tabular}

Notes: ${ }^{* * *} \mathrm{P}<0.001 ;{ }^{* *} \mathrm{P}<0.01 ;{ }^{*} \mathrm{P}<0.05$

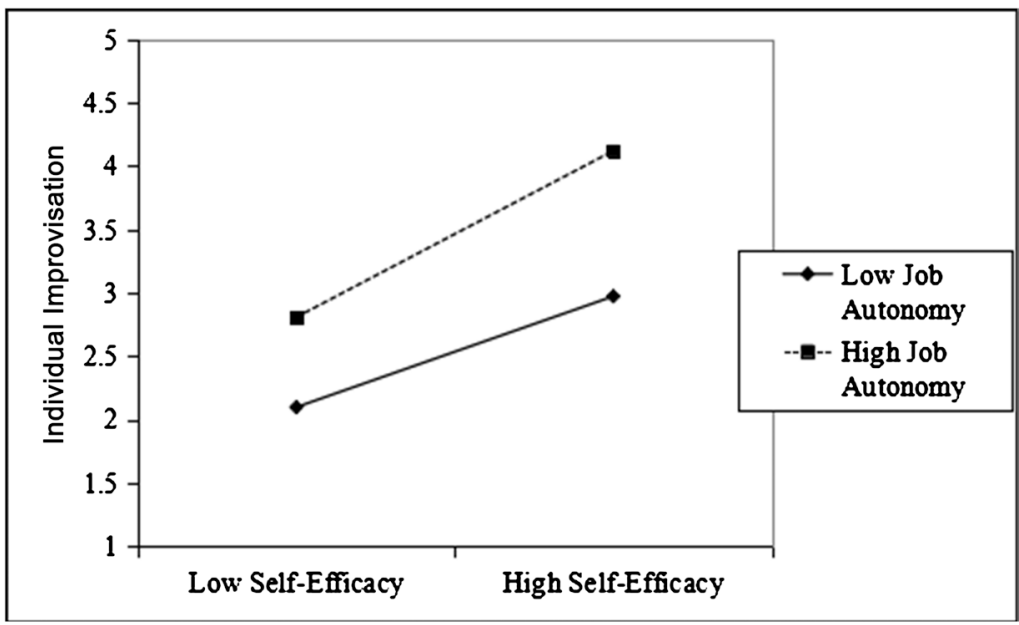

Figure 3. The regulation effect of job autonomy. 
management. Facing the uncertainty of the environment, the individual improvisation can bring innovation and get rid of the difficulties for organization. This study combines social cognitive theory and job characteristics model theory. Based on the previous studies, self-efficacy is used as a mediator and job autonomy as a moderator. From the perspective of psychological resources, this paper studies the relationship between proactive personality and employee improvisation relationship. The main conclusions are as follows: proactive personality positively affects employee's improvisational behavior; self-efficacy plays a partial intermediary role between proactive personality and employee improvisational behavior; job autonomy can strengthen the relationship between self-efficacy and employee improvisation behavior.

\subsection{Theoretical and Practical Implications}

The theoretical contributions of this article are as follows. First, our research extends the research on the antecedent variables of individual improvisational behaviors. Through empirical research, we find that proactive personality traits play an active role in influencing employees' improvisational behaviors. Individuals with proactive personality are not bound by the environment and adept in discovering opportunities, then generating positive improvisations to change the environment. Secondly, previous studies found that self-efficacy plays a mediating role in the influence mechanism of proactive personality on individual behavior. This paper regards self-efficacy as a mediator to construct a intermediary path that "proactive personality-self-efficacy-individual improvisation". This intermediary path reveals the internal mechanism of the influence of proactive personality on employee improvisation behavior, that is, the individuals with high proactive personality generate the higher self-confidence of self-ability, and are more likely to generate behavioral motivation and the improvisational behavior. Finally, this study confirms that job autonomy plays a regulatory role in the process of self-efficacy-driven improvisation, it provides a new theoretical basis for the organization to give employees more autonomy. It is of great significance to promote work autonomy theory and the development of work design practice.

Our study has various important implications for practice. First, the evaluation of the personality traits and psychological characteristics of candidates should be highly valued. In order to cope with the uncertainty and variability of the environment, enterprises need to evaluate the proactive personality traits of employees in the recruitment, select employees with high initiative and self-efficacy, and achieve matching between people and posts. Secondly, enterprises should pay attention to the cultivation and management of employees' self-efficacy in the usual management, improve the ability and quality of employees through training, strengthen the self-motivation education of employees, and formulate more scientific and effective incentive mechanisms. Finally, organizations should increase environmental autonomy, especially work methods 
and workplace autonomy, so that employees can choose the solution to the problem more independently and have full freedom to play and Improvise.

\subsection{Limitations and Future Research Directions}

The expecting findings from the present study also have several limitations which should take into consider. First, the empirical data used in this study is the static data of the cross-section. It cannot fully reflect the dynamic relationship between self-efficacy and employee Improvisation. Therefore, future research can try to use vertical data and time series data to study the dynamic relationship. Secondly, this study focuses on individual improvisation from the perspectives of individual personality traits and work characteristics, while the influencing factors also include other individual psychological factors and organizational support factors, we should pay attention to those factors. Third, in this study, only the intermediary mechanism of self-efficacy was verified, there are other possible mechanisms or regulatory factors waiting to be explored.

\section{Conclusion}

In this paper, we used 298 samples to examine our hypotheses. Through confirmatory factor analyses (CFAs) and multilevel modeling analyses, we found that proactive personality will be positively related to individual improvisation, and self-efficacy partly mediates the relationship of them. Meanwhile, job autonomy and self-efficacy have an interaction effect on individual Improvisation. These findings are helpful in managing and utilizing employee improvisation, that is, enterprises need to select employees with high initiative and self-efficacy to cope with the uncertainty and variability of the environment; meanwhile, organizations should increase environmental autonomy, which can encourage more improvisational behaviors. In the future, we encourage a further exploration about the topic.

\section{Conflicts of Interest}

The authors declare no conflicts of interest regarding the publication of this paper.

\section{References}

[1] Crossan, M., Cunha, M.P.E. and Cunha, V.J. (2005) Time and Organizational Improvisation. The Academy of Management Review, 30, 129-145. https://doi.org/10.5465/amr.2005.15281441

[2] Vera, D. and Crossan, M. (2005) Improvisation and Innovative Performance in Teams. Organization Science, 16, 203-224. https://doi.org/10.1287/orsc.1050.0126

[3] Smets, M., Morris, T. and Greenwood, R. (2012) From Practice to Field: A Multilevel Model of Practice-Driven Institutional Change. Academy of Management Journal, 55, 877-904. https://doi.org/10.5465/amj.2010.0013

[4] Cunha, M.P.E., Cunha, J.V. and Kamoche, K. (2003) Organizational Improvisation: 
What, When, How and Why. International Journal of Management Reviews, 1, 299-341. https://doi.org/10.1111/1468-2370.00017

[5] Magni, M., Proserpio, L., Hoegl, M. and Provera, B. (2009) The Role of Team Behavioral Integration and Cohesion in Shaping Individual Improvisation. Research Policy, 38, 1044-1053. https://doi.org/10.1016/j.respol.2009.03.004

[6] Ding, D.R. and Chen, W.M. (2017) A Study about the Impact of Self-Efficacy on Individual Improvisation: The Mediating Effect of Expectation of Individual Outcome and the Moderating Effect of Organizational Support. Forcasting, 36, 21-27.

[7] Bateman, T. and Crant, M.J. (2010) The Proactive Component of Organizational Behaviour: A Measure and Correlates. Journal of Organizational Behavior, 14, 103-118. https://doi.org/10.1002/job.4030140202

[8] Chen, C.F. and Kao, Y.L. (2014) Investigating the Moderating Effects of Service Climate on Personality, Motivation, Social Support, and Performance among Flight Attendants. Tourism Management, 44, 58-66. https://doi.org/10.1016/j.tourman.2014.02.012

[9] Brown, D.J., Cober, R.T., Kane, K. and Levy, P.E. (2006) Proactive Personality and the Successful Job Search: A Field Investigation with College Graduates. Journal of Applied Psychology, 91, 717-726. https://doi.org/10.1037/0021-9010.91.3.717

[10] Latham, G.P. and Pinder, C.C. (2005) Work Motivation Theory and Research at the Dawn of the Twenty-First Century. Annual Review of Psychology, 56, 485-516. https://doi.org/10.1146/annurev.psych.55.090902.142105

[11] Weick, K.E. (1998) Introductory Essay: Improvisation as a Mind Set for Organizational Analysis. Organization Science, 9, 534-555. https://doi.org/10.1287/orsc.9.5.543

[12] Fuller, B. and Marler, L.E. (2009) Change Driven by Nature: A Meta-Analytic Review of the Proactive Personality Literature. Journal of Vocational Behavior, 75, 329-345. https://doi.org/10.1016/j.jvb.2009.05.008

[13] Thompson, A. and Jeffery, A. (2005) Proactive Personality and Job Performance: A Social Capital Perspective. Journal of Applied Psychology, 90, 1011-1017. https://doi.org/10.1037/0021-9010.90.5.1011

[14] Bandura, A. (2015) On Deconstructing Commentaries Regarding Alternative Theories of Self-Regulation. Journal of Management, 21, 1025-1044. https://doi.org/10.1177/0149206315572826

[15] Bindl, U.K. and Parker, S.K. (2011) Proactive Work Behavior: Forward-Thinking and Change-Oriented Action in Organizations. In: Sheldon, Z., Ed., APA Handbook of Industrial and Organizational Psychology, American Psychological Association, Washington, Vol. 2, 567-598. https://doi.org/10.1037/12170-019

[16] Brown, D.J., Cober, R.T., Kane, K. and Levy, P.E. (2006) Proactive Personality and the Successful Job Search: A Field Investigation with College Graduates. Journal of Applied Psychology, 91, 717-726. https://doi.org/10.1037/0021-9010.91.3.717

[17] Gist, M.E. (1987) Self-Efficacy: Implications for Organizational Behavior and Human Resource Management. Academy of Management Review, 12, 472-485. https://doi.org/10.5465/amr.1987.4306562

[18] Seibert, S.E., Crant, J.M. and Kraimer, M.L. (1999) Proactive Personality and Career Success. Journal of Applied Psychology, 84, 416-27. https://doi.org/10.1037/0021-9010.84.3.416

[19] Parker, S.K., Williams, H.M. and Turner, N. (2006) Modeling the Antecedents of Proactive Behavior at Work. Journal of Applied Psychology, 91, 636-652. 
https://doi.org/10.1037/0021-9010.91.3.636

[20] Spiegelaere, S.D., Gyes, G.V. and Hootegem, G.V. (2016) Not All Autonomy Is the Same: Different Dimensions of Job Autonomy and Their Relation to Work Engagement \& Innovative Work Behavior. Human Factors and Ergonomics in Manufacturing \& Service Industries, 26, 515-527. https://doi.org/10.1002/hfm.20666

[21] Hackman, J.R. and Oldham, G.R. (1976) Motivation through the Design of Work: Test of the Theory. Organizational Behavior and Human Performance, 16, 250-279. https://doi.org/10.1016/0030-5073(76)90016-7

[22] Men, Y., Fan, Y. and Ma, G.M. (2016) How Cognitive-Emotional Factors Influence Team Members' Improvisation: The Main and Moderation Effects. Forcasting, 35, 17-22.

[23] Wang, A.C. and Cheng, B.S. (2010) When Does Benevolent Leadership Lead to Creativity? The Moderating Role of Creative Role Identity and Job Autonomy. Journal of Organizational Behavior, 31, 106-121. https://doi.org/10.1002/job.634

[24] Parker, S.K. (1998) Enhancing Role Breadth Self-Efficacy: The Roles of Job Enrichment and Other Organizational Interventions. Journal of Applied Psychology, 83, 835-852. https://doi.org/10.1037/0021-9010.83.6.835

[25] Schwarzer, R., Babler, J., Kwiatek,P., Schroder, K. and Zhang, J.X. (1997) The Assessment of Optimistic Self-Beliefs: Comparison of the German, Spanish, and Chinese Versions of the General Self-Efficacy Scale. Applied Psychology, 46, 69-88. https://doi.org/10.1111/j.1464-0597.1997.tb01096.x

[26] Spreitzer, G.M. (1995) Psychological Empowerment in the Workplace: Dimensions, Measurement, and Validation. Academy of Management Journal, 38, 1442-1465. 